\title{
Responses of vegetation cover to the Grain for Green Program and their driving forces in the He-Long region of the middle reaches of the Yellow River
}

\author{
JianXiang LIU $^{1,2^{*}}$, ZhiGuang $\mathrm{LI}^{3}$, XiaoPing ZHANG ${ }^{1}$, Rui $\mathrm{LI}^{1}$, XianChun LIU ${ }^{3}$, HanYang ZHANG ${ }^{4}$ \\ ${ }^{1}$ State Key Laboratory of Soil Erosion and Dryland Farming on Loess Plateau, Institute of Soil and Water Conservation, Chinese Acad- \\ emy of Sciences and Ministry of Water Resources, Xi'an 712100, China; \\ ${ }^{2}$ Graduate University of Chinese Academy of Sciences, Beijing 100049, China; \\ ${ }^{3}$ Soil and Water Conservation Monitoring Centre, the Ministry of Water Resources of the People's Republic of China, Beijing 100053, \\ China; \\ ${ }^{4}$ Workers Sanatorium of the Yellow River, Xi'an 710600, China
}

\begin{abstract}
The implementation of the Grain for Green Program is a great breakthrough in the history of China's ecological environment construction, which can control soil erosion effectively, increase land productivity and improve the ecological environment. To investigate the eco-environmental benefits brought by the Grain for Green Program, the spatiotemporal variations of vegetation cover in the growing season from 2000 to 2010 across the Hekou-Longmen (He-Long) region were analyzed by using remote sensing information, meteorological data and land use data. Moreover, the impacts of climate and human activities on vegetation change were evaluated objectively. Annual vegetation cover in the growing season increased very significantly. Increased vegetation cover occurred in $98.7 \%$ of the region, of which the area for vegetation cover improved slightly constituted $79.8 \%$ of the whole area. Vegetation moderately improved was mainly distributed in the south of the He-Long region, covering $9.6 \%$ of the area, and the area for vegetation basically unchanged concentrated in the middle and upper reaches of the Wuding River. Precipitation was found to be an important natural factor influencing vegetation cover change. The area of vegetation cover showing a significantly positive correlation with precipitation occupied $22.14 \%$ of the region. As driven by policies from the Grain for Green Program, forestland increased significantly and land use structure became more intensive. Human activities played a positive and effective role in the protection, restoration and improvement of vegetation in the places where vegetation cover was basically unchanged, even though precipitation declined greatly, and vegetation improved moderately with massive increases of forestland and grassland.
\end{abstract}

Keywords: vegetation cover; precipitation; land use; the Grain for Green Program; the He-Long region

Citation: JianXiang LIU, ZhiGuang LI, XiaoPing ZHANG, Rui LI, XianChun LIU, HanYang ZHANG. 2013. Responses of vegetation cover to the Grain for Green Program and their driving forces in the He-Long region of the middle reaches of the Yellow River. Journal of Arid Land, 5(4): 511-520. doi: 10.1007/s40333-013-0177-8

Being closely related to biodiversity (Dupouey et al., 2002), climate (Matthews, 1983; Zhang et al., 2012) and ecological environment changes (Chen et al., 2009) and in particular, human activities, land use/land cover change is the main cause of global environmental variations (Turner et al., 1994). As a re- sult from human activities, land use emphasizes the use of natural attributes of land by humankind. According to the system theory of structure determining functions (Von Bertalanffy, 1969), the quantity of land use and its spatial structure are the key to a land use system. Land cover is the natural state of the earth's

*Corresponding author: JianXiang LIU (E-mail: syx.1985@163.com)

Received 2012-10-23; revised 2012-12-23; accepted 2013-01-23

(C) Xinjiang Institute of Ecology and Geography, Chinese Academy of Sciences, Science Press and Springer-Verlag Berlin Heidelberg 2013 
land surface and near-surface layer, with vegetation being a major component, and is the outcome of natural processes as incorporated with human activities. Land use is an important driving force to land cover change, most of which is determined by human land utilization (Turner et al., 1993).

To solve the environmental problems like soil erosion and land desertification, the Chinese government initiated the Grain for Green Program, one of the world's largest conservation programs, in 26 provinces and autonomous regions of China in 1999. The program serves as a policy driving force in adjusting regional land use structure and landscape pattern (Zhang et al., 2012). The program was designed to establish a land use/land cover pattern with ecological security ( $\mathrm{Li}$ et al., 2004). After the two stages of experimental demonstration (from 1999 to 2001) and program implementation (from 2002 to 2010), the effects of the program began to appear in improving soil, conserving water (Fu et al., 2010), increasing farmers' income (Zhou et al., 2007), optimizing rural industrial structure, and enhancing human awareness of environment protection (Li et al., 2010).

The Loess Plateau located in the middle reaches of the Yellow River, especially the He-Long (short for Hekou-Longmen) region, is suffering from the severest soil erosion in China, even in the world. The He-Long region is the main source area of coarse sediment production and responsible for sediment siltation on the downstream riverbed of the Yellow River, and the sediments from the He-Long region contribute $60 \%$ of the annual sediment yield of the Yellow River (Soil and Water Conservation Monitoring Centre, the Ministry of Water Resources of the People's Republic of China, 2011).

Years from 2011 to 2020 are the later consolidation stage of the program, during which the main tasks are woodland protection and management and local reforestation ( $\mathrm{Li}, 2004)$. Analyzing the distribution of vegetation cover and its spatiotemporal variations and objectively evaluating the eco-environmental benefits from human activities are of great significance to consolidate the reforestation achievements and control soil erosion effectively in the He-Long region.

To evaluate the benefits of the Grain for Green Pro- gram and provide a basis for making a strategy of eco-environmental construction rationally and efficiently in the current stage, the distribution of vegetation cover and its spatiotemporal variations across the He-Long region from 2000 to 2010 were studied based on MODIS-NDVI, precipitation and land use data. Moreover, driving factors were discussed, such as climate indicated by precipitation and land use as a result from human activities.

\section{Study area and methods}

\subsection{Study area}

The $11.3 \times 10^{4} \mathrm{~km}^{2} \mathrm{He}$-Long region is in the upstream drainage area in the middle reaches of the Yellow River. The region has a temperate continental climate characterized by an annual mean temperature varying from 6 to $14^{\circ} \mathrm{C}$ and a mean annual precipitation ranging from 300 to $550 \mathrm{~mm}$. Moreover, rainfall mostly occurs from July to September, accounting for $66 \%$ of the annual total precipitation. From southeast to northwest, vegetation was extensively distributed in the subzones of forest steppe, arid steppe and desert steppe.

Agricultural land and grassland are the main land use types in the He-Long region and cover $22.9 \%$ and $55.7 \%$ of the whole region, respectively ( $\mathrm{Li}$ et al., 2009). Annual runoff from the region is $7.7 \times 10^{9} \mathrm{~m}^{3}$, which occupies $13.8 \%$ of the annual total runoff of the Yellow River. Annual sediment yield averages $9.08 \times 10^{8} \mathrm{t}$ (Shi, 1993). About $83.45 \%$ of the total land area suffers from severe soil erosion, and the areas of moderate and serious erosion amount to $26 \%$ and $25 \%$ of the total soil erosion area, respectively (Dong et al., 2012). The He-Long region is one of the main source areas of flooding and sediment yield, especially coarse sediment, in the Yellow River basin. The proportion of steep sloping land to total land is $10 \%-40 \%$. Irrational land use and seriously damaged vegetation are the most important factors for the serious soil and water loss in the region (Li et al., 2008).

Under the Grain for Green Program, sloping arable lands were gradually converted to forestland or grassland. The implementation of the program has great significance for adjusting land use structure, restoring 
forest and grassland cover, controlling soil erosion and improving eco-environmental conditions.



Fig. 1 The locations of the Loess Plateau (light grey in the upper small map) and the He-Long region (dark grey in the upper small map) in the middle reaches of the Yellow River, and the main catchments (grey in the lower large map) in the He-Long region. Number 1, the Gushan River basin; 2, the Kuye River basin; 3, the Wuding River basin; 4, the Qingjian River basin; 5, the Yan River basin; 6, the Shiwang River basin; 7, the Xinshui River basin; 8, the Sanchuan River basin; 9, the Zhujia River basin; and 10, the Pianguan River basin.

\subsection{Data}

The MODIS-NDVI data, product of MOD13Q1 from 2000 to 2010 used in the study, were issued by NASA (National Aeronautics and Space Administration) at a space resolution of $250 \mathrm{~m} \times 250 \mathrm{~m}$ and with a 16-day interval. The data format was EOS-HDF. To eliminate the impacts of cloud, atmosphere, solar elevation angle, etc., the data underwent such pretreatments as radiometric and atmospheric corrections (Huete et al., 1999).

Precipitation data were obtained from China Meteorological Administration and some county weather stations. Krigging method was employed to interpo- late precipitation at monthly and growing seasonal scales. Land use data were acquired from Landsat TM of 1997 and 2010 by experts' interpretation.

\subsection{Methods}

\subsubsection{Trend of vegetation cover change}

By using the MRT (MODIS Reprojection Tools) offered by NASA, the original MOD13Q1 data were processed for pretreatments, including subset extraction, image mosaic and projection transformation, to acquire NDVI dataset. Monthly NDVI was then calculated using the maximum value composite method for the purpose of further eliminating the interferences of cloud, atmosphere and sun elevation angle (Tucker et al., 1994). Only the vegetation cover in the growing season from April to October was investigated because the land surface was usually covered by snow during the rest of the year and vegetation cover was basically unchanged, and the existence of snow may lead to large errors between NDVI values and actual vegetation status (Wang, 2005).

Trend analysis was made to reveal the change of vegetation cover with time in each month and throughout the growing season. To analyze the spatial distribution of vegetation in the growing season from 2000 to 2010, NDVI was divided into three levels (low vegetation cover, NDVI value of less than 0.35 ; medium vegetation cover, NDVI value of $0.35-0.55$; high vegetation cover, NDVI value of more than 0.55 ) by a certain range of NDVI value (Chen et al., 2008).

Linear regression analysis was made for annual NDVI value at each pixel (Stow et al., 2003) in order to study the spatial variation of vegetation cover across the region (Eq. 1). The equation for the trend slope of vegetation cover change is:

$$
S=\frac{n \times \sum_{i=1}^{n}\left(i \times N D V I_{i}\right)-\left(\sum_{i=1}^{n} i\right)\left(\sum_{i=1}^{n} N D V I_{i}\right)}{n \times \sum_{i=1}^{n} i^{2}-\left(\sum_{i=1}^{n} i\right)^{2}} .
$$

Where $S$ is the trend slope of vegetation cover change at each pixel; $i$, the year; $n$, the number of the years; and $N D V I_{i}$, the NDVI value computed in the growing season of each year. When $S$ is greater than zero, it means that vegetation cover increases; otherwise, vegetation cover is decreased. In this sense, the value 
of $S$, to a certain extent, reflects the degree of vegetation change at each pixel.

The slope of vegetation cover change at each pixel was classified into seven groups with reference to the grading standards by Song and Ma (2007), which have been used in studying the vegetation cover in Northwest China (Table 1).

Table 1 Statistical result of the NDVI-value ranges

\begin{tabular}{ll}
\hline NDVI-value range & Classification \\
\hline$\leq-0.0360$ & Severely degraded \\
$-0.0360--0.0198$ & Moderately degraded \\
$-0.0198--0.0036$ & Slightly degraded \\
$-0.0036-0.0036$ & Basically unchanged \\
$0.0036-0.0198$ & Slightly improved \\
$0.0198-0.0360$ & Moderately improved \\
$\geq 0.0360$ & Significantly improved \\
\hline
\end{tabular}

1.3.2 Land use information extraction

Prior to interpretation, the images were processed for such pretreatments as geometric rough rectification, geometry rectification, image mosaic and cropping, image enhancement, etc (Liang and Yang, 2004). Based on the needs of this study and the expert's understanding on the object's spectral reflectance, structure and other information, the interpretation signs of 6 classes of land cover (farmland, grassland, forestland, residential land, water, and unused land) were established, in association with the erosion and geomorphologic features of the He-Long region. In the process of interpretation, a variety of auxiliary data were used, including climate, soil type, DEM, geology, topography and vegetation. Moreover, field observation was carried out to assist the interpretation (Zhang, 2007).

1.3.3 Influence factors for vegetation cover change Some methods adopted in the study of the variation of vegetation cover were also used to analyze the variation of precipitation. For evaluating the effect of precipitation on NDVI, the correlation between precipitation and NDVI was determined using the equation (Buermann et al., 2003):

$$
\gamma=\frac{n \times \sum_{i=1}^{n}\left(N D V I_{\mathrm{i}} \times P_{i}\right)-\left(\sum_{i=1}^{n} N D V I_{\mathrm{i}}\right) \times\left(\sum_{i=1}^{n} P_{i}\right)}{\sqrt{n \times \sum_{i=1}^{n} N D V I_{i}^{2}-\left(\sum_{i=1}^{n} N D V I_{\mathrm{i}}\right)^{2}} \times \sqrt{n \times \sum_{i=1}^{n} P_{i}^{2}-\left(\sum_{i=1}^{n} P_{i}\right)^{2}}} .
$$

Where $\gamma$ is the correlation coefficient; $n$, the number of the years; $N D V I_{i}$, the NDVI value in the growing season of a specific year; $P_{i}$, precipitation in the growing season of a specific year; and $N D V I_{i} \times P_{i}$, the product of NDVI value and precipitation in the growing season of a specific year. When $\gamma$ is greater than zero, it means that NDVI has a positive correlation with precipitation; otherwise, it indicates a negative or no correlation with precipitation.

The correlation coefficient $\gamma$ was subject to significance test using the following equation (Deng, 2009):

$$
t=\frac{\gamma}{\sqrt{1-\gamma^{2}}} \sqrt{(n-2)}
$$

Where $\gamma$ is the correlation coefficient; and $n$, the number of samples. When $t \leq 0.01$, it means that the correlation coefficient is significant; and when $t \leq 0.05$, it indicates high significance.

Land use data of 1997 and 2010 were contrasted to illustrate the quantitative change of land use after the program. Land use transition matrix was established to analyze the land use transition situation during 1997 and 2010. Moreover, for a quantitative description of the landscape patterns of land use and the change situation, structural characteristics (Fernandes et al., 2011) were analyzed at class and landscape scales by means of landscape indices, including the number of patches (NP), mean patch size (MPS), largest patch index (LPI) and contagion index.

\section{Results and discussion}

\subsection{Spatiotemporal distribution and variation of vegetation cover}

\subsubsection{Temporal variation of vegetation cover}

NDVI of the growing season shows a significant increasing trend with a slope of 0.0112 , and increased from 0.238 to 0.401 with a change rate of $68.5 \%$ from 2000 to 2010, which implies that the vegetation condition was significantly improved in the He-Long region.

As showed in Fig. 2, NDVI values manifest an increasing trend when they were examined separately for each of the seven months in the growing season. The increasing trend of monthly NDVI is most evident in July, August and September and the 
corresponding trend slopes are $0.0133,0.0130$, and 0.0132, respectively, which implies that NDVI changes in the three months made a major contribution to the improvement of vegetation cover. The maximum average monthly NDVI 0.4765 appeared in August, the medium 0.4403 in July, and the minimum 0.2212 in April. The NDVI change rate was the greatest in May (65.7\%). It follows from the trend lines that NDVI values in May manifested a steadily increasing trend as examined at annual scale and however, NDVI values in August had the lowest change rate of $29.5 \%$.
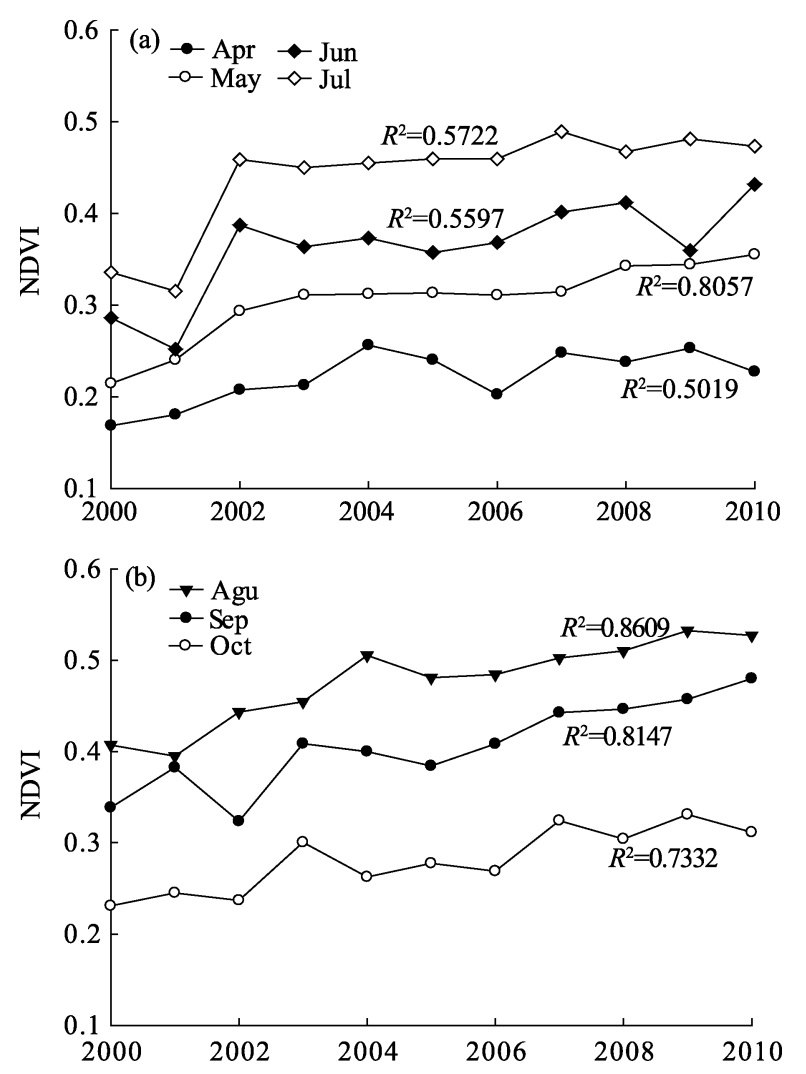

Fig. 2 Monthly NDVI variation for every month of the growing season from 2000 to 2010

2.1.2 Spatial distribution and variation of vegetation cover

On the whole, low vegetation cover occupied a largest area of $6.81 \times 10^{4} \mathrm{~km}^{2}$, which was $60.41 \%$ of the whole He-Long region; moderate vegetation cover, an area of $3.41 \times 10^{4} \mathrm{~km}^{2}$, constituting $30.25 \%$; and high vegetation cover accounted for $9.34 \%$ only. To the west of the Yellow River, the basins located in the north of the
Wuding River had relatively low vegetation cover; most of the Yan River and Qingjian River basins to the south of the Wuding River had moderate vegetation cover; and other basins had high vegetation cover. The basin to the east of the Yellow River, on the whole, had better status of vegetation cover.

Through the trend analysis of annual NDVI in the growing season, it was found that the area with increased NDVI trend occupied $98.7 \%$ of the total study area, whereas the area with decreased NDVI trend, only $1.3 \%$ (Fig. 3). By the statistics for the change degrees classified in Table 1, vegetation slightly improved covered a largest area of up to $9.01 \times 10^{4} \mathrm{~km}^{2}$ and constituted $79.9 \%$ of the whole region. The area for vegetation basically unchanged ranked second, being up to $1.12 \times 10^{4} \mathrm{~km}^{2}$ and $10.0 \%$ of the whole region. The area for vegetation moderately improved accounted for $9.6 \%$ of the region. The areas of vegetation significantly improved, slightly degraded, moderately degraded and severely degraded were all very small and can be neglected. Accordingly, vegetation cover in the region can be considered to be, on the

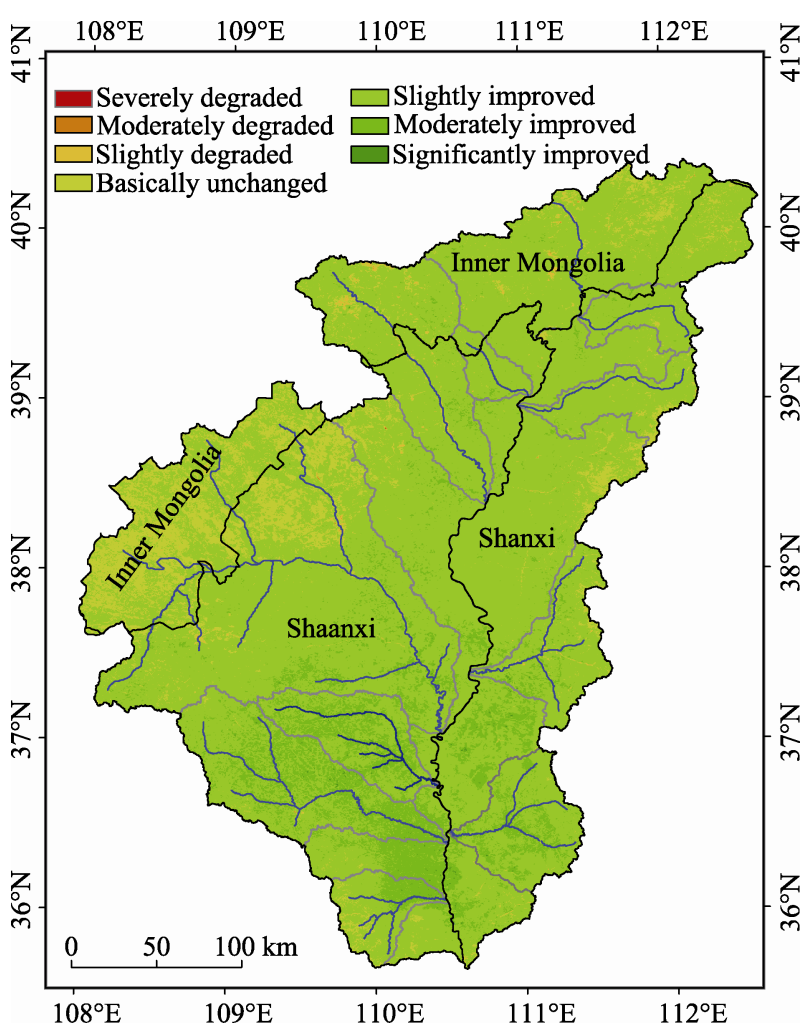

Fig. 3 Trends of the average annual NDVI in the growing season from 2000 to 2010 
whole, in a status of improvement. Vegetation basically unchanged is mainly distributed in the northern area of the middle-upper reaches of the Wuding River. Vegetation moderately improved is mainly distributed between the Qingjian and Shiwang rivers, south to the Sanchuan River, and in most parts of the Xinshui River basin. In other areas, vegetation presented a slightly improved trend.

\subsection{Analysis of influencing factors}

\subsubsection{Influence of precipitation on NDVI evolution}

Annual precipitation averaged $391.565 \mathrm{~mm}$ over the study period of 2000-2010. High precipitation was distributed in the east and south of the region and was basically identical to the area with high vegetation cover, which means that the amount of precipitation was a key factor to influence vegetation cover. Overall, precipitation showed an insignificant increasing trend with a slope of 0.830 (Fig. 4). Specifically, precipitation declined in $45.5 \%$ while rose in $54.5 \%$ of the region. Declined precipitation mainly occurred in the west and south of the He-Long region and violently declined precipitation was found in the middle-upper reaches of the Wuding River. On the contrary, strongly increased precipitation was observed in the area between the Zhujia and Shanchuan rivers located in the east of the Yellow River and mid-eastern Shanxi province. Figure 4 illustrates that the NDVI trends were generally consistent with the variation of precipitation at an annual scale, except that precipitation significantly decreased, while NDVI continuously increased after 2007. A primary cause of NDVI decrease from 2004 to 2005 was that precipitation

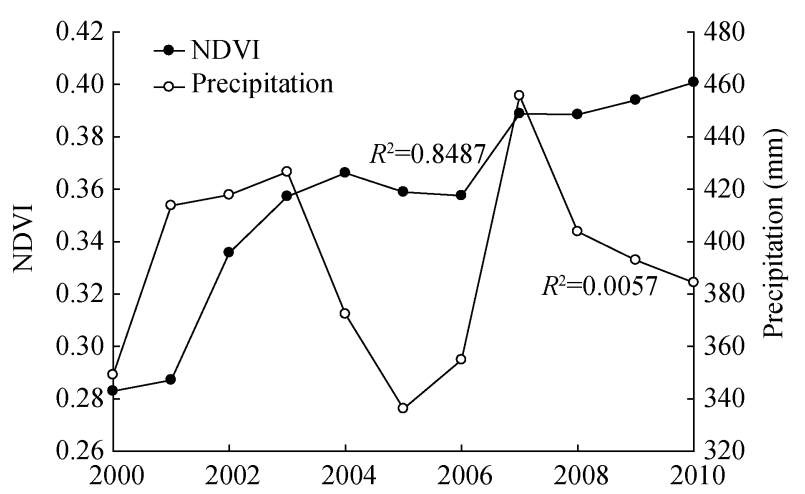

Fig. 4 Trends of the annual precipitation and NDVI in the growing season from 2000 to 2010 was reduced from 372.31 to $336.17 \mathrm{~mm}$ at a rate of $9.7 \%$ during that period.

Figures 5 and 6 present the correlation coefficients and their significance of annual NDVI and precipitation in the growing season from 2000 to 2010 . The area for the positive correlation of annual NDVI with annual precipitation covered $73.3 \%$ of the region, and contrarily, the area for the negative correlation covered only $26.7 \%$. Moreover, the area for the significantly positive correlation was $2.49 \times 10^{4} \mathrm{~km}^{2}$, accounting for $22.14 \%$ of the region, and the area for the significantly negative correlation accounted for $1.05 \%$ of the region. Similar to the change of precipitation, the areas for the negative correlation mainly concentrated in the south and west of the He-Long region and for the positive correlation, between the north of the Sanchuan River and the east of the Yellow River, as well as in the north of the Gushan River. Increased vegetation cover in these areas was mainly affected by increased precipitation.

The area for vegetation basically unchanged was located in the north of the middle-upper reaches of the

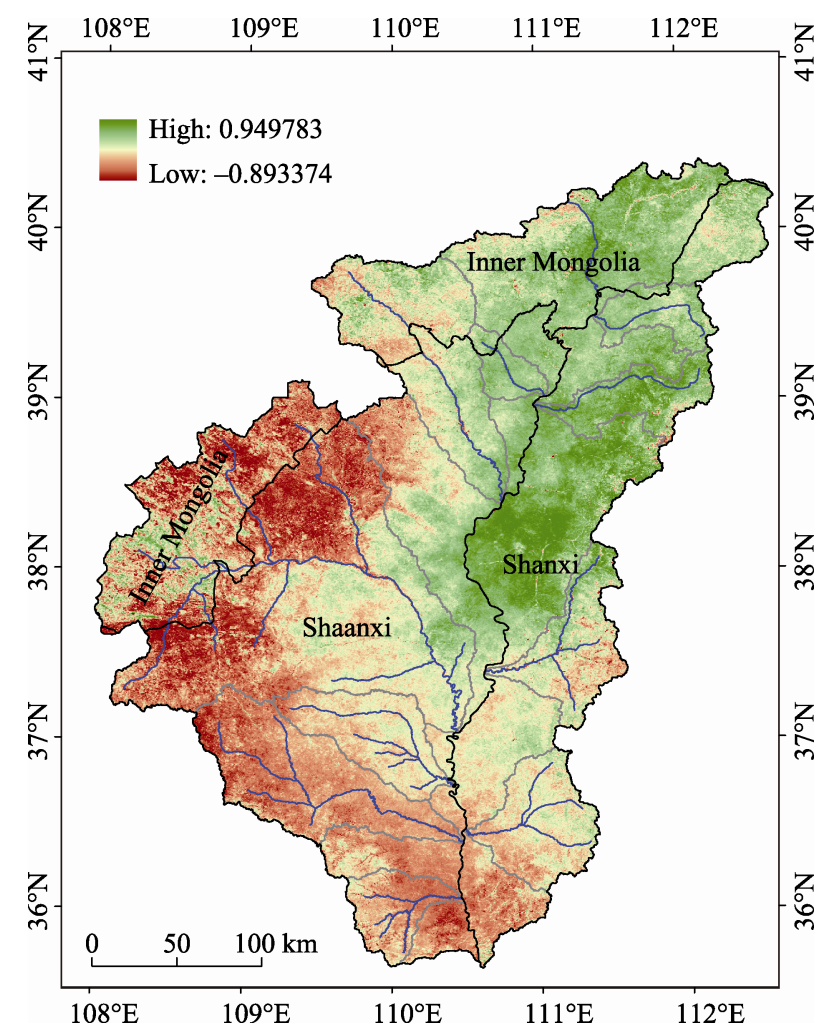

Fig. 5 Correlation coefficients for annual NDVI and precipitation in the growing season from 2000 to 2010 


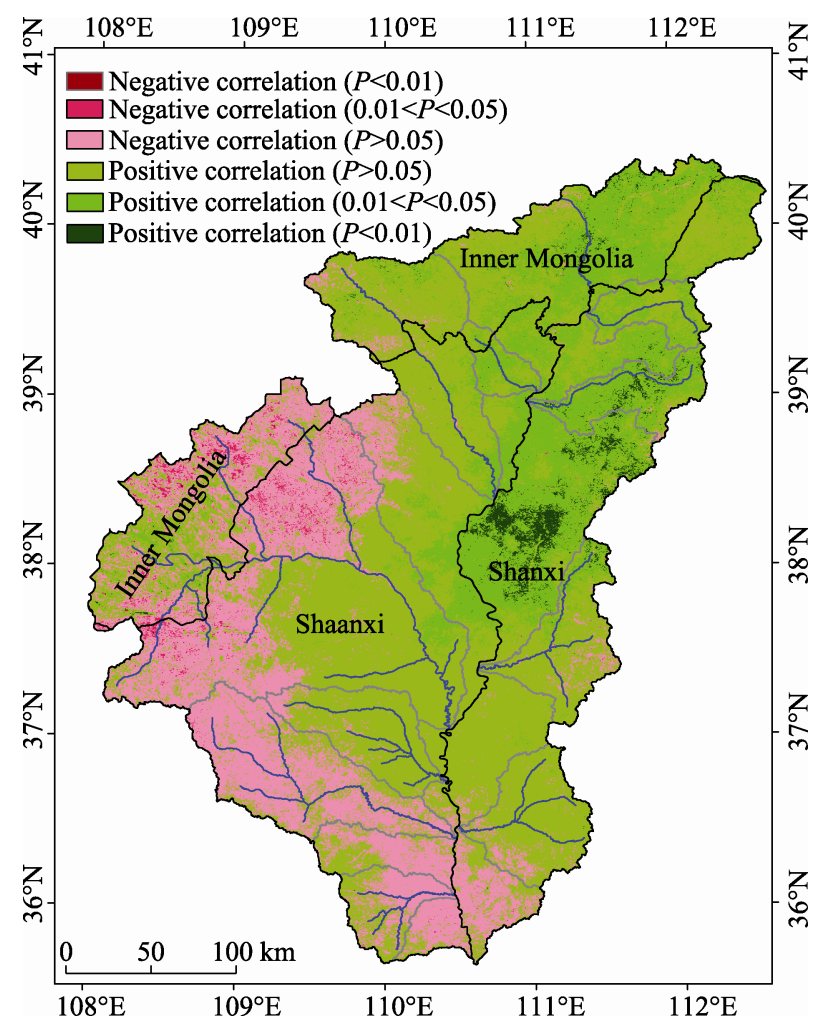

Fig. 6 Significance of correlation coefficients for annual NDVI and precipitation in the growing season from 2000 to 2010

Wuding River where precipitation declined extraordinarily. In the area, NDVI has a negative correlation with precipitation and the correlation coefficient is high, which indicates a positive effect of human activities on vegetation protection ( $\mathrm{Li}$ et al., 2009).

All the areas for vegetation moderately improved present a negative correlation between NDVI and precipitation and in particular, the negative correlation coefficients are high in the areas between the Yan and Shiwang rivers, with the exception that the areas in the south of the Sanchuan River and the Xinshui River basins present a low positive correlation, moreover, the correlation is not significant. The result shows that the areas for vegetation moderately improved were mainly influenced by human activities (Xin et al., 2007; Liu et al., 2011).

\subsubsection{Influence of human activities}

In 1997, grassland was the main land use type and occupied $50.24 \%$ of the total area (Table 2). Farmland was the second largest land use type with a proportion of $28.23 \%$ of the total area. The areas of forestland and unused land accounted for $12.27 \%$ and $8.53 \%$ of the total area, respectively. Until 2010, the area of grassland changed little and increased by $0.44 \%$ only, whereas the area of farmland decreased by $18.87 \%$. The area of forestland rose to $19,395.83 \mathrm{~km}^{2}$ with a proportion of $17.23 \%$ of the total area. The area of unused land decreased by $13.88 \%$. Residential land and water areas changed violently. Proportions of the areas of residential land and water to the whole area were increased from $0.07 \%$ and $0.65 \%$ to $1.02 \%$ and $10.3 \%$, respectively.

According to the analysis of land use transition matrix (Table 2), the implementation of the Grain for Green Program greatly reduced the area of farmland,

Table 2 Transition matrix of land use in the He-Long region from 1997 to 2010

\begin{tabular}{|c|c|c|c|c|c|c|c|c|}
\hline & \multirow{2}{*}{ Index } & \multicolumn{7}{|c|}{2010} \\
\hline & & Farmland & Grassland & Forestland & Residential land & Water & Unused land & Area in 1997 \\
\hline \multirow{13}{*}{1997} & Farmland $\left(\mathrm{km}^{2}\right)$ & $12,164.57$ & $15,771.39$ & $2,787.04$ & 356.07 & 321.40 & 387.81 & $31,788.27$ \\
\hline & Proportion $(\%)$ & 38.27 & 49.61 & 8.77 & 1.12 & 1.01 & 1.22 & \\
\hline & Grassland $\left(\mathrm{km}^{2}\right)$ & $12,404.11$ & $31,679.42$ & $9,598.87$ & 590.73 & 387.91 & $1,907.28$ & $56,568.31$ \\
\hline & Proportion (\%) & 21.93 & 56.00 & 16.97 & 1.04 & 0.69 & 3.37 & \\
\hline & Forestland $\left(\mathrm{km}^{2}\right)$ & 715.85 & $5,464.83$ & $6,868.03$ & 60.58 & 25.53 & 673.99 & $13,808.81$ \\
\hline & Proportion (\%) & 5.18 & 39.57 & 49.74 & 0.44 & 0.18 & 4.88 & \\
\hline & Residential land $\left(\mathrm{km}^{2}\right)$ & 8.59 & 10.62 & 2.33 & 44.79 & 13.86 & 0.82 & 81.02 \\
\hline & Proportion (\%) & 10.60 & 13.11 & 2.87 & 55.29 & 17.11 & 1.02 & \\
\hline & Water $\left(\mathrm{km}^{2}\right)$ & 94.14 & 189.99 & 17.74 & 10.66 & 358.49 & 56.19 & 727.20 \\
\hline & Proportion (\%) & 12.95 & 26.13 & 2.44 & 1.47 & 49.30 & 7.73 & \\
\hline & Unused land $\left(\mathrm{km}^{2}\right)$ & 401.02 & $3,699.41$ & 121.82 & 80.97 & 56.84 & $5,252.78$ & $9,612.83$ \\
\hline & Proportion (\%) & 4.17 & 38.48 & 1.27 & 0.84 & 0.59 & 54.64 & \\
\hline & Area in $2010\left(\mathrm{~km}^{2}\right)$ & $25,788.28$ & $56,815.65$ & $19,395.83$ & $1,143.79$ & $1,164.02$ & $8,278.87$ & $112,586.45$ \\
\hline
\end{tabular}


and the reduced farmland was mainly converted to grassland and forestland. Generally, grassland increased little and the grassland was mainly converted to farmland and forestland, with the proportions of $21.93 \%$ and $16.97 \%$ of the total grassland area, respectively. The increased area of forestland was mainly contributed by the increase of grassland and farmland areas. The decrease in farmland area resulted from its conversion to grassland and the increase in forestland area, largely from the increase of grassland. Most of the unused land was sandy land and the decreased unused land was mainly transformed to grassland with a proportion of $38.48 \%$ of the total unused area.

The analyses of land use type change and transition matrix testify that the Grain for Green Program had brought better eco-environmental benefits in this region. The area of forestland increased significantly. Some of the sandy land and farmland were converted to grassland and forestland, which made land use pattern change dramatically. By the analysis of landscape pattern of land use from 1997 to 2010, NP for farmland, grassland, forestland and unused land decreased greatly and the total NP decreased by $95.19 \%$ (Table 3). The MPS increased significantly, which means that land use types, on the whole, presented an increasing trend. It indicates that land use pattern had changed from fragmentation and high heterogeneity to centralization in the region. For farmland, the LPI was reduced by $61 \%$, whereas for forestland, it increased by $58 \%$. This illustrates that the gradual conversion of farmland to forestland could efficiently increase the area of forestland as driven by the policies from the Grain for Green Program. Contagion index for the whole landscape increased from 45.36 to 53.14 , which indicates that there was a superior patch type with better connectivity in the landscape.

Table 3 Landscape pattern parameters of land use in the He-Long region from 1997 to 2010

\begin{tabular}{|c|c|c|c|c|c|c|c|c|}
\hline \multirow{2}{*}{ Landscape type } & \multicolumn{4}{|c|}{1997} & \multicolumn{4}{|c|}{2010} \\
\hline & Area $\left(\mathrm{km}^{2}\right)$ & NP & MPS $\left(\mathrm{km}^{2}\right)$ & LPI (\%) & Area $\left(\mathrm{km}^{2}\right)$ & NP & MPS $\left(\mathrm{km}^{2}\right)$ & LPI $(\%)$ \\
\hline Farmland & $31,788.27$ & 465,354 & 6.8328 & 3.5019 & $25,788.28$ & 28,500 & 90.4882 & 1.3653 \\
\hline Grassland & $56,568.31$ & 314,615 & 17.9796 & 38.8501 & $56,815.65$ & 12,036 & 472.0544 & 19.8544 \\
\hline Forestland & $13,808.81$ & 385,460 & 3.5842 & 2.5283 & $19,395.83$ & 13,301 & 145.8470 & 3.9881 \\
\hline Residential land & 81.02 & 5,890 & 1.3787 & 0.0065 & $1,143.79$ & 5,182 & 22.0672 & 0.0359 \\
\hline Water & 727.20 & 19,369 & 3.7527 & 0.0826 & $1,164.02$ & 1,241 & 93.7905 & 0.3049 \\
\hline Unused land & $9,612.83$ & 142,922 & 6.7281 & 0.9738 & $8,278.87$ & 3,838 & 215.7399 & 1.1973 \\
\hline Total NP & & $1,333,610$ & & & & 64,0980 & & \\
\hline $\operatorname{MPS}\left(\mathrm{km}^{2}\right)$ & & & 6.7094 & & & & 173.3312 & \\
\hline Contagion index & & 45. & & & & 53. & & \\
\hline
\end{tabular}

Note: $\mathrm{NP}=$ Number of patches, MPS=Mean patch size, LPI=Large patch index.

The middle-upper reaches of the Wuding River is located in the west margin of the Mu Us Desert where vegetation cover is basically unchanged and a fragile ecological environment exists (Jin et al., 2011). Drought stress is the dominant factor influencing the survival and growth of vegetation (Zhang et al., 2011). Some studies showed that natural vegetation would degenerate and vegetation cover would decrease in the case of continuous drought (Wang et al., 2010). In the background of violently reduced precipitation, human activities played a positive role in vegetation protection, as driven by the Grain for Green Program (Wu and Zou, 2010). The program has resulted in better eco-environmental benefits in the area between the Yan and Shiwang rivers where widely increased forestland and grassland played a crucial role in improving vegetation (Zhang and Wei, 2008).

By the analysis of the quantity of land use and its spatial structure, it was found that traditional planting practices like extensive cultivation were changed, irrational land use structure was adjusted effectively ( $\mathrm{Li}$, 2004), and land use became more intensive. The area of forestland increased efficiently, while the area of farmland decreased obviously, which had an active 
effect on vegetation cover improvement in the study region. However, the area of grassland changed little and the proportion of the largest grassland patch area to the whole landscape showed a decreasing trend, which means that grassland protection and recovery should be strengthened in the future.

\section{Conclusions}

Annual vegetation cover in the growing season increased very significantly in the He-Long region. Vegetation cover increased in every month of the growing season, during which the increasing trend slopes of vegetation cover are greater in July, August and September. On the whole, low vegetation cover had the largest area. Vegetation cover status was the best in Shanxi province and the worst in Inner Mongolia autonomous region. Spatially, the area for increased vegetation cover in the growing season accounted for $98.7 \%$ of the study region, and for decreased vegetation cover, only $1.3 \%$. Vegetation slightly improved had the largest area, followed by vegetation basically unchanged and then vegetation moderately improved.

The area for high precipitation was basically consistent with that for high vegetation cover. The amount of precipitation was found to be an important factor influencing the degree of vegetation coverage in the He-Long region. Overall, precipitation showed an insignificant increasing trend in the region. There is a positive correlation between precipitation and NDVI in $73.3 \%$ of the total area. Furthermore, the area for significantly positive correlation covered $22.14 \%$ of the total area, where improved vegetation cover was mainly affected by precipitation.

Land use structure underwent a great adjustment in the He-Long region. The main land use type was grassland. From 1997 to 2010, forestland was significantly increased by $40.46 \%$, but farmland was reduced by $18.87 \%$, with the reduced farmland being largely converted to grassland and forestland. Land use pattern changed from high fragmentation and heterogeneity to an intensive pattern. The newly increased area of vegetation moderately improved was mainly contributed by the appearance of a large area of forestland, which proves that human activities played a positive and effective role in vegetation cover improvement as driven by the policies from the Grain for Green Program. However, the area of grassland was basically unchanged and moreover, the proportion of the largest grassland patch area to the total landscape area showed a decreasing trend. More efforts need to be made in grassland protection and restoration in the He-Long region.

\section{Acknowledgements}

This research was funded by the funding from the Chinese Academy of Sciences (KZCX2-XB3-13, KZZD-EW-04-03), the National Science Foundation of China (41230852, 41101265) and China Census for Water. The authors thank the National Aeronautics and Space Administration, China Meteorological Administration and the county weather stations in the He-Long region for data provision.

\section{References}

Buermann W, Anderson B, Tucker C J, et al. 2003. Interannual covariability in Northern Hemisphere air temperatures and greenness associated with El Nino-Southern Oscillation and the Arctic Oscillation. Journal of Geophysical Research, 108(D13): 1-11.

Chen C C, Xie G D, Zhen L, et al. 2008. Analysis on Jinghe watershed vegetation dynamics and evaluation on its relation with precipitation. Acta Ecologica Sinica, 28(3): 925-938.

Chen X L, Li S J, Guo Z X, et al. 2009. Analysis on the harmonious degree between land use and ecological environment in Yanbian Korean Autonomous Prefecture, Jilin Province. China Land Science, 23(7): 66-70.

Deng J X. 2009. Probability Theory and Mathematical Statistics. Beijing: Higher Education Press

Dong Y W, Wu Y H, Ma W X, et al. 2012. Analysis on effectiveness of soil and water conservation in Hekou Town-Longmen sector based on remote sensing monitoring. Journal of Water Resources and Water Engineering, 23(1): 157-160.

Dupouey J L, Dambrine E, Laffite J D, et al. 2002. Irreversible impact of past land use on forest soils and biodiversity. Ecology, 83(11): 2978-2984.

Fernandes M R, Aguiar F C, Ferreira M T. 2011. Assessing riparian vegetation structure and the influence of land use using landscape metrics and geostatistical tools. Landscape and Urban Planning, 99(2): 166-177.

Fu X L, Shao M A, Wei X R, et al. 2010. Soil organic carbon and total nitrogen as affected by vegetation types in Northern Loess Plateau of China. Geoderma, 155(1-2): 31-35.

Huete A, Justice C, Van Leeuwen W. 1999. MODIS Vegetation Index (MOD13) Algorithm Theoretical Basis Document. Tucson: Univer- 
sity of Arizona.

Jin Y, Meng J J, Huang J. 2011. Grassland ecological vulnerability assessment of Mu Us Desert in recent 50 years: a case study of Wushen Banner. Acta Scientiarum Naturalium Universitatis Pekinensis, 47(5): 909-915.

Li G, Liang W, Yang Q K. 2009. Analysis of land use pattern change in coarse sandy region of middle reaches of Yellow River. Science of Soil and Water Conservation, 7(3): 52-58.

Li N, Han H R, Zhang X X. 2009. Research on vegetation coverage change and its impact factors in Wuqi Country, Shaanxi Province. Journal of Arid Land Resources and Environment, 23(6): 114-119.

Li R, Yang W Z, Li B C, et al. 2008. Research and Future Prospects for the Loess Plateau of China. Beijing: Science Press.

Li S D. 2004. Research on Conversion of Farmland to Forest in China. Beijing: Science Press.

Li X B, Shi P J, Jiang Y. 2004. Land Use/Cover Change and Ecosystem Security. Beijing: Science Press.

Li Z H, Li X Q, Tang L N, et al. 2010. Spatio-temporal dynamic analysis of an island city landscape: a case study of Xiamen Island, China. International Journal of Sustainable Development \& World Ecology, 17(4): 273-278

Liang W, Yang Q K. 2004. Dynamic analysis of regional land-use change by remote sensing. Ph.D. Dissertation. Beijing: Graduate University of Chinese Academy of Sciences.

Liu Z H, Guo W L, Yang Q K, et al. 2011. Vegetation cover change and their relationship with rainfall in different physiognomy type areas of Loess Plateau. Science of Soil and Water Conservation, 9(1): 16-23.

Matthews E. 1983. Global vegetation and land use: new high-resolution data bases for climate studies. Journal of Applied Meteorology, 22(3): 474-487.

Shi M L. 1993. Hydrological analysis of the variation of runoff and sediment from Hekouzhen-Longmen intermediate basin of the Yellow Rive. Soil and Water Conservation in China, 14(4): 15-18.

Soil and Water Conservation Monitoring Centre, the Ministry of Water Resources of the People's Republic of China. 2011. Research on Methods of Soil Erosion Dynamic Monitoring. Beijing: China Water Power Press.

Song Y, Ma M G. 2007. Study on vegetation cover change in Northwest China based on SPOT VEGETATION data. Journal of Desert Research, 27(1): 89-93.

Stow D, Daeschnera S, Hopea A, et al. 2003. Variability of the seasonally integrated normalized difference vegetation index across the north slope of Alaska in the 1990s. International Journal of Remote Sensing, 24(5): 1111-1117.

Tucker C J, Newcomb W W, Dregne H E. 1994. AVHRR data sets for determination of desert spatial extent. International Journal of Remote Sensing, 15(17): 3547-3565.

Turner B L, Ross R H, Skole D, et al. 1993. Relating land-use and global land cover change (IGBP Report No.24, IHDP Report No.5). Stockholm and Geneva: IGBP of the ICSU and IHDP of the ISSC.

Turner B L, Meyer W B, Skole D L. 1994. Global land-use/land-cover change: towards an integrated study. Ambio, 23(1): 91-95.

Von Bertalanffy L. 1969. General System Theory: Foundations, Development, Applications. New York: George Braziller, Inc.

Wang L X, Liu H M, Yang J, et al. 2010. Climatic change of Mu Us Sandy Land and its influence on vegetation coverage. Journal of Natural Resources, 25(12): 2030-2039.

Wang Y R. 2005. Response of droughts or waterloggings in the Loess Plateau in China to global climate change. Arid Land Geography, 28(2): 161-166.

Wu X X, Zou X Y. 2010. Analysis of landscape pattern change and its driving factors based on $3 \mathrm{~S}$ technology: a case study in Uxin Banner of Inner Mingolia. Journal of Desert Research, 30(4): 763-769.

Xin Z B, Xu J X, Zheng W. 2007. Impact of climate change and human activities on vegetation cover change in the Loess Plateau. Science in China: Earth Science, 37(11): 1504-1514.

Zhang D Z, Qu S Y, Sun Z F. 2011. The effect and solution of water shortage on plant community in Mu Us sandland. Inner Mongolia Forest Investigation and Design, 34(5): 36-38, 101.

Zhang H, Tong W J, Wang N, et al. 2012. Analysis on landscape pattern of land-use in Horqin Sandy Land on the background of conversion of cultivated land to grassland. Journal of Arid Land Resources and Environment, 26(6): 96-101.

Zhang X P. 2007. Responses of streamflow to land use/cover change in He-Long region, the middle reaches of Yellow River, China. Ph.D Dissertation. Beijing: Graduate University of Chinese Academy of Sciences.

Zhang Z G, Wei J J. 2008. Influence of returning cropland to forest and grassland on ecosystem service value of downstream Yanhe River. Chinese Journal of Eco-Agriculture, 16(3): 737-740.

Zhou S, Yin Y, Xu W, et al. 2007. The costs and benefits of reforestation in Liping County, Guizhou Province, China. Journal of Environmental Management, 85(3): 722-735. 